\title{
Dual-Analyte Chronopotentiometric Aptasensing Platform Based on a G-Quadruplex/Hemin DNAzyme and Logic Gate Operations
}

\author{
Shuwen Liu, ${ }^{\dagger, \S}$ Jiawang Ding, ${ }^{*}+, \neq \odot$ and Wei Qin*, ${ }^{\dagger}, \neq \odot$ \\ ${ }^{\dagger}$ Key Laboratory of Coastal Environmental Processes and Ecological Remediation and Shandong Provincial Key Laboratory of \\ Coastal Environmental Processes, Yantai Institute of Coastal Zone Research (YIC), Chinese Academy of Sciences (CAS), Yantai, \\ Shandong 264003, P. R. China \\ ${ }^{\ddagger}$ Laboratory for Marine Biology and Biotechnology, Qingdao National Laboratory for Marine Science and Technology, Qingdao \\ 266200, P. R. China \\ ${ }^{\S}$ University of the Chinese Academy of Sciences, Beijing 100049, P. R. China
}

Supporting Information

ABSTRACT: Conventional potentiometric ion sensors that rely on a specific ion carrier in a polymeric membrane can hardly achieve multianalyte detection. Inspired by the remarkable ability of built-in logic gate sensors for multianalyte detection, herein we report a potentiometric aptasensing platform based on a G-quadruplex/hemin DNAzyme and logic gate operations for determination of

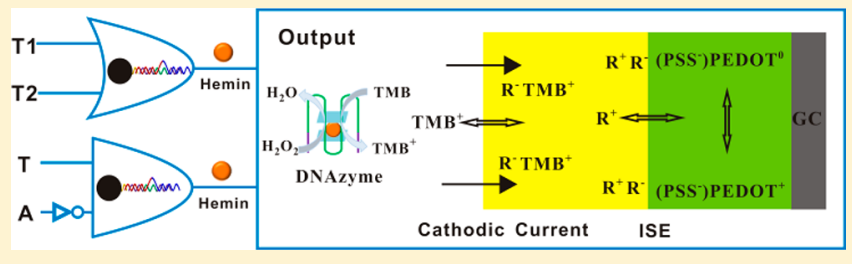
two analytes using a single membrane electrode. A bifunctional probe with two aptamer units and a signal reporter oligonucleotide with a DNAzyme sequence are assembled on the magnetic beads to form a DNA hybrid structure. The "OR" and "INHIBIT" logic functions can be performed by using the two aptamers and their targets as inputs, and using the chronopotentiometric response based on the G-quadruplex/hemin DNAzyme- $\mathrm{H}_{2} \mathrm{O}_{2}$-mediated oxidation of 3,3',5,5' -tetramethylbenzidine as output. Kanamycin and oxytetracycline, as commonly used antibiotics, have been employed as the models and successfully measured.

A s one of the most commonly used electrochemical sensors, potentiometric polymeric membrane ion-selective electrodes (ISEs) have served as a simple yet powerful tool for measuring ions in biological and environmental samples. ${ }^{1-10}$ Conventionally, an ISE membrane contains an ion carrier as receptor and responds to the activity of one specific ion in a Nernstian way. ${ }^{11}$ Potentiometric sensing of multiple analytes cannot be performed using such a single ISE. In recent years, the introduction of dynamic electrochemistry techniques has opened up a new aspect of ISEs. ${ }^{12}$ In addition to the new trends in developing attractive methodologies using novel readout principles, ${ }^{13-18}$ the use of a single membrane electrode to achieve multianalyte detection has been pursued. Various methods have been developed for this purpose based on thinlayer voltammetry and coulometry, ${ }^{19-23}$ tandem dynamic potentiometry-principle component analysis, ${ }^{24}$ and column separation-chronopotentiometry. ${ }^{25}$ However, these methods are limited to multi-ion detection. More recently, we proposed a chronopotentiometric genosensor for detection of two DNA sequences based on the sandwich assay. ${ }^{26}$ However, this method requires enzyme labeling. Therefore, it is still an open challenge to develop a facile and general strategy for detection of multiple neutral molecules other than ionic species using a single membrane electrode.

Boolean logic gates are physical devices that exert logical operations by receiving one (or more) chemical process as an input and yielding one (or more) easily detectable analytical signal as an output. ${ }^{27-29}$ Activated by specific inputs (targets), logical operations have been adopted for sensing applications. The sensors with built-in logic gates hold the inherent capability to analyze multianalytes. ${ }^{30-35}$ Moreover, diverse logic gate systems can be designed based on different inputs and output signals. To the best of our knowledge, logic gate operations employing potential responses of ISEs as outputs have not been reported.

Aptamers are short oligonucleotides selected in vitro to bind a broad range of molecular targets with high specificities and good affinities. ${ }^{36-39}$ Moreover, some DNA sequences are capable of recruiting hemin as a cofactor to form DNAzymes. These DNAzymes, which mimic the catalytic activities of enzymes and stimulate a wide variety of catalytic reactions, ${ }^{40-44}$ can be incorporated into an aptamer binding event and extensively used as amplifying labels for aptasensing. In recent years, DNAzyme- ${ }^{45-52}$ and aptamer-based ${ }^{53-56}$ logic gates have been successfully constructed to emulate Boolean operations and implement sensing applications. More importantly, a diverse range of logic gates can be easily designed and used for multianalyte detection. Inspired by these advantages, we envisioned that, by coupling the potentiometry with the logic operations, an intelligent and versatile platform

Received: December 29, 2018

Accepted: January 16, 2019

Published: January 16, 2019 
can be developed to achieve dual- or multianalyte detection using a single membrane electrode. Moreover, by integration of biorecognition elements with the potentiometric measurements, highly sensitive and selective measurements of a broad range of different molecular targets other than ionic species can be expected.

Herein, as a proof of concept experiment, a potentiometric aptasensing platform based on G-quadruplex/hemin DNAzyme and logic gate operations was designed for dual-analyte potentiometric detection. Kanamycin (KANA) and oxytetracycline (OTC), as the extensively used antibiotics that can result in drug resistance in bacteria, were employed as the models. A bifunctional oligonucleotide with two aptamer units at its lateral portions is used as probe for dual analysis and bound to the surface of magnetic beads. A signal reporter oligonucleotide with a DNAzyme sequence hybridizes with probe DNA to form a DNA hybrid structure. The "OR" and "INHIBIT" logic functions were performed by using the two aptamers and their targets as inputs, and the chronopotentiometric response based on the G-quadruplex/hemin DNAzyme$\mathrm{H}_{2} \mathrm{O}_{2}$-mediated oxidation of $3,3^{\prime}, 5,5^{\prime}$-tetramethylbenzidine as an output. While commonly used transduction modes based on the colorimetric and fluorescent detection are available, ${ }^{41}$ the proposed chronopotentiometric mode promises to be a competitive transducer for peroxidase-mimicking DNAzymeinvolved biosensing due to their unique features such as low cost, ease of miniaturization, and resistance to color and turbid interferences. It is anticipated that such a potentiometric aptasensing platform can be applicable for detection of other targets, for which aptamer sequences are available, serving as a promising tool for developing multianalyte detection using a single electrode.

\section{EXPERIMENTAL SECTION}

Reagents and Materials. All the oligonucleotides were obtained from Sangon Biotechnology Co., Ltd. (Shanghai, China). The sequences of the synthetic oligonucleotides are listed in Table S1. Hemin; 3,3',5,5'-tetramethylbenzidine (TMB); poly(sodium 4-styrenesulfonate) (NaPSS); 3,4-ethylenedioxythiophene (EDOT); antibiotics including kanamycine, chloramphenicol, streptomycin, oxytetracycline, ampicillin, streptomycin, and gentamicin; high-molecular-weight poly(vinyl chloride) (PVC); tetradodecylammonium tetrakis(4-chlorophenyl)-borate (ETH 500); and 2-nitropheny octyl ether (o-NPOE) were purchased from Sigma-Aldrich (St. Louis, MO). Streptavidin-labeled magnetic beads (MBs, $10 \mathrm{mg}$ $\mathrm{mL}^{-1}$ ) with an average particle size of $1.0 \mu \mathrm{m}$ were purchased from BioCanal Scientific Inc. (Wuxi, China). Tris-borateEDTA (TBE) buffer was purchased from Solarbio (Beijing, China). Acrylamide, bis(acrylamide), and $N, N, N^{\prime}, N^{\prime}$-tetramethylethylenediamine (TEMED) were purchased from Macklin (Shanghai, China). DNA marker (20 bp DNA ladder, 3420A) was obtained from TAKARA BIO INC. All other chemical reagents were purchased from Sinopharm Chemical Reagent (Shanghai, China). All chemicals were analytical grade and used without further purification. The stock solution of hemin $(100 \mu \mathrm{M})$ was prepared in dimethyl sulfoxide (DMSO) and stored in darkness at $-20{ }^{\circ} \mathrm{C}$. A $10 \mathrm{mM}$, Tris- $\mathrm{HCl}$ buffer of $\mathrm{pH} 7.4$ containing $20 \mathrm{mM} \mathrm{KCl}, 200 \mathrm{mM} \mathrm{NaCl}$, and $1.0 \mathrm{mM}$ EDTA was used as hybridization and detection buffers.

Membrane Preparation and EMF Measurements. The ion-selective membranes containing 10 wt \% ETH 500, 45 wt $\% \mathrm{PVC}$, and $45 \mathrm{wt} \% o$-NPOE were prepared as described before. ${ }^{26}$ Poly(3,4-ethylenedioxythiophene) polystyrene sulfonate (PEDOT/PSS) films were synthesized on glass carbon (GC, $3 \mathrm{~mm}$ in diameter) electrodes by applying a current of $0.014 \mathrm{~mA}$ for $714 \mathrm{~s}$ in aqueous solution containing $0.1 \mathrm{M}$ NaPSS and $0.01 \mathrm{M}$ EDOT as described before. ${ }^{57}$ After the polymerization, the membrane cocktail of $80 \mu \mathrm{L}$ was drop-cast on the GC/PEDOT/PSS and dried at room temperature. The electrodes were conditioned in the Tris- $\mathrm{HCl}$ hybridization buffer overnight. All chronopotentiometric measurements were carried out at room temperature using a CHI 660E electrochemical work-station (Shanghai Chenhua Apparatus Corporation, Shanghai, China). A conventional three-electrode cell with membrane electrode as the working electrode, a platinum wire as auxiliary electrode, and $\mathrm{Ag} / \mathrm{AgCl}(3.0 \mathrm{M} \mathrm{KCl})$ as reference electrode was used.

DNA Hybrid-Structure-Functionalized Magnetic Beads. Before use, all the oligonucleotides in the Tris- $\mathrm{HCl}$ hybridization buffer were heated at $95{ }^{\circ} \mathrm{C}$ for $5 \mathrm{~min}$ to dissociate any intermolecular interactions and then cooled quickly in an ice-water mixture. ${ }^{58}$ The bifunctional probe and the signal reporter oligonucleotide were immobilized on the magnetic beads via DNA hybridization. The 5'-biotin-modified capture DNA $(100 \mu \mathrm{L}, 10 \mu \mathrm{M})$ was first incubated with the streptavidin-modified magnetic beads $\left(100 \mu \mathrm{L}, 10 \mathrm{mg} \mathrm{mL}^{-1}\right)$ with $30 \mathrm{~min}$ of shaking at room temperature via the biotinstreptavidin interaction. After magnetic separation and washing with the hybridization buffer, the capture-DNA-modified magnetic beads were obtained. The capture-DNA-modified magnetic beads were then incubated with $5 \mu \mathrm{M}$ of the bifunctional probe and that of the signal reporter with shaking at room temperature for $1 \mathrm{~h}$. After magnetic separation and washing with hybridization buffer, the hybrid-structurefunctionalized magnetic beads (FMBs) were obtained. The FMBs of $25 \mu \mathrm{L}$ were used for the incubation with the target.

Denaturing Urea Polyacrylamide Gel Electrophoresis. The signal reporter released from the FMBs was detected by using denaturing urea polyacrylamide gel electrophoresis (PAGE). A gel (polyacrylamide) percentage of $15 \%$ was selected depending on the oligonucleotide length. A $15 \mathrm{~mL}$ gel solution containing $5.6 \mathrm{~mL}$ of acrylamide stock solution (38\% acrylamide and $2 \%$ bis(acrylamide) ), $1.5 \mathrm{~mL}$ of $10 \times \mathrm{TBE}, 660$ $\mu \mathrm{L}$ of $1.6 \%$ ammonium persulfate, $10 \mu \mathrm{L}$ of TEMED, $7 \mathrm{M}$ urea, and $7.23 \mathrm{~mL}$ of deionized water was prepared. The oligonucleotides in loading buffer were denatured at $95{ }^{\circ} \mathrm{C}$ for $5 \mathrm{~min}$ and cooled quickly on ice. The supernatant products were then loaded on the PAGE gel $(83 \times 73 \times 1 \mathrm{~mm})$. Electrophoreses were run in $1 \times \mathrm{TBE}$ for $30 \mathrm{~min}$ at a constant voltage of $80 \mathrm{~V}$ and then at $100 \mathrm{~V}$ for $90 \mathrm{~min}$. The gel was silver-stained as described before. ${ }^{59}$ During each step, the gels were rinsed immediately with deionized water quickly for $30 \mathrm{~s}$ after the liquid was removed.

Dual-Antibiotic Detection. For the "OR" logic gate operation, $1.0 \mu \mathrm{L}$ of KANA or OTC at different concentrations was first incubated with $25 \mu \mathrm{L}$ of the FMBs in the hybridization buffer with $1 \mathrm{~h}$ of shaking at room temperature. After magnetic separation, $1.0 \mu \mathrm{L}$ of a $10 \mu \mathrm{M}$ hemin solution was added to the supernatant, and the mixture was incubated at room temperature for $1 \mathrm{~h}$ to form the G-quadruplex/hemin DNAzyme. Then, $1.0 \mu \mathrm{L}$ of $10 \mathrm{mM}$ TMB and $2.0 \mu \mathrm{L}$ of 10 $\mathrm{mM} \mathrm{H}_{2} \mathrm{O}_{2}$ were added into the DNAzyme solution to react for $10 \mathrm{~min}$. Finally, $50 \mu \mathrm{L}$ of the above reaction solution was added into $450 \mu \mathrm{L}$ of $10 \mathrm{mM} \mathrm{pH} 7.4$ Tris- $\mathrm{HCl}$ buffer for 
chronopotentiometric measurements. Control experiments were done following the same procedures.

For the "INHIBIT" logic gate operation, $1.0 \mu \mathrm{L}$ of $1.0 \mu \mathrm{M}$ of the KANA aptamer or OTC aptamer was incubated with 100 $\mu \mathrm{L}$ of hybridization buffer containing $0.1 \mu \mathrm{M}$ KANA or OTC for $30 \mathrm{~min}$, and then, $100 \mu \mathrm{L}$ of hybridization buffer incubated with FMBs with $1 \mathrm{~h}$ of shaking at room temperature. The following steps are the same with the "OR" logic gate.

Determination of KANA and OTC in Real Samples. The standard addition method was used for determination of KANA and OTC in real water samples. Before measurements, the samples were buffered Tris- $\mathrm{HCl}$ of $\mathrm{pH} 7.4$, and then spiked with different amounts of KANA or OTC. For measurements of KANA and OTC, the OTC and KANA aptamers $(100 \mu \mathrm{M}, 1.0 \mu \mathrm{L})$ were added into $100 \mu \mathrm{L}$ samples and incubated for $30 \mathrm{~min}$ to inhibit the responses to OTC and KANA, respectively. For the combinatorial logic gate operations, separate reaction mixtures were prepared to perform as either the "OR" or "INHIBIT" logic gate.

\section{RESULTS AND DISCUSSION}

Magnetic beads (MBs) with promising applications in bioseparation and bioassays were used as the carrier to construct a DNA hybrid structure. The DNA hybrid structure consists of a bifunctional oligonucleotide that includes two aptamer units for KANA and OTC and a signal reporter nucleic acid with the DNAzyme sequence in the middle and two complementary regions at its $3^{\prime}$ and $5^{\prime}$ ends. ${ }^{60,61}$ The sequences of synthetic oligonucleotides are listed in Table S1. The bifunctional probe was immobilized on the magnetic beads via capture DNA. Then, the bifunctional probe was blocked by the signal reporter via a hybrid structure (Figure 1A). The immobilization efficiency was measured by UV-vis
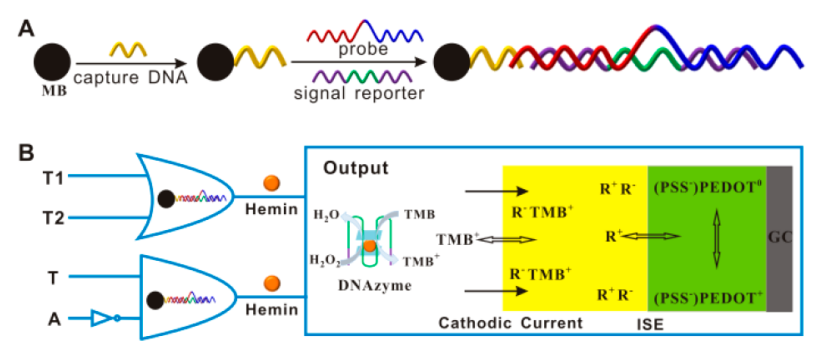

Figure 1. Schematic illustrations of (A) the formation of a DNA hybrid structure on magnetic beads (MBs) and (B) the principle of a potentiometric aptasensing platform based on the "OR" and "INHIBIT" logic gates. The bifunctional oligonucleotide includes one aptamer unit for KANA (sequence, TGGGGGTTGAGGCTAAGCCGA; in blue), one aptamer unit for OTC (sequence, CGGTGGTG; in red), and other sequences (as shown in Table S1). The signal reporter nucleic acid contains the DNAzyme sequence in the middle (sequence, TGGGTAGGGGGGGTTGGGGGGAGACCCACT; in green) and two complementary regions at the $3^{\prime}$ and $5^{\prime}$ ends (sequences, 3 '-AGACCCACT; 5'-CCCAGGTCACT; in purple).

spectroscopy, and the concentrations of the probe and signal reporter in the magnetic fluid were ca. 1.0 $\mu \mathrm{M}$. UV-vis spectroscopy verifies the formation of the modified hybrid structure magnetic beads (Figure S1). Figure 1B outlines the principle of a potentiometric aptasensing platform based on the construction of the "OR" and "INHIBIT" logic gates. In this logic system, antibiotics KANA (T1)/OTC (T2) and
DNAzyme-modulated chrono-potentials were used as inputs and outputs, respectively.

Our previous research shows that the oxidation of TMB by the $\mathrm{HRP} / \mathrm{H}_{2} \mathrm{O}_{2}$ system can induce a large cationic potential response on an ion exchanger-based polymeric membrane electrode. ${ }^{62}$ In this study, the $\mathrm{H}_{2} \mathrm{O}_{2}$-mediated oxidation of TMB by the G-quadruplex/hemin complex was investigated via the chronopotentiometric method. For the chronopotentiometric measurements, the procedures switching between the galvanostatic and potentiostatic steps were designed according to our previous research, which enables reproducible chronopotentiometric response and multiple consecutive measurements. ${ }^{26}$ The open-circuit potential of the electrode in hybridization buffer was first recorded for $1 \mathrm{~s}$. Then, a cathodic pulsed current of $2 \mu \mathrm{A}$ with a duration of $1 \mathrm{~s}$ was applied, which was followed by using a constant potential for $90 \mathrm{~s}$ to refresh the membrane. The chrono-potential difference $(\Delta E)$ between the baseline and the chrono-potential response in the presence of target were used for quantification. As expected, the positively charged oxidation intermediates of TMB can be extracted into the polymeric membrane to produce a chronopotentiometric response (Figure S2). Moreover, a linear relationship between the potential response and the DNAzyme concentration was obtained in the range 10$500 \mathrm{nM}$ (Figure S3). Therefore, the G-quadruplex/hemin DNAzyme $-\mathrm{H}_{2} \mathrm{O}_{2}$-mediated oxidation of TMB can be adopted as the output.

The target-binding-induced release of the signal reporter is essential to achieve logic operations. The mechanism of the intermolecular interactions can be obtained by the molecular dynamics simulation. ${ }^{39}$ The molecular docking analysis reveals that KANA and OTC can interact with the appropriate sequences in their aptamers and the regions that hybridize with the complementary regions of probe, thus leading to the release of the signal reporter (more details are available in the Supporting Information and Figure S4). The CDOCKER interaction energy calculated for the KANA $(-142.64 \mathrm{kcal}$ $\left.\mathrm{mol}^{-1}\right)$ is higher than that of OTC $\left(-36.62 \mathrm{kcal} \mathrm{mol}^{-1}\right)$, indicating that the target T1 (KANA) induces the signal reporter released from the MBs more easily. As proven by the UV-vis spectroscopic and the chronopotentiometric measurements, the target antibiotic can bind to the aptamer sequence in the probe, which induces the release of the signal reporter strand from the hybrid structure (Figure S2). Thus, in the presence of hemin, the G-quadruplex/hemin complexes (DNAzyme) with the peroxidase activity can catalyze the $\mathrm{H}_{2} \mathrm{O}_{2}$-mediated oxidation of TMB to produce a large chronopotentiometric response. While the duplex structure of the signal reporter is opened by the respective target, the performance of the proposed assay could be improved when both KANA aptamer and OTC aptamer sequences are partially blocked by the signal reporter. Moreover, the exact amount of the aptamer sequence blocked should be optimized, especially when the surrounding medium is different. Control experiments clearly demonstrate that no obvious potential changes can be observed in the absence of KANA or OTC. It should be noted that hemin itself possesses a weak catalytic activity.

For the acquisition of highly sensitive chronopotentiometric measurements, parameters including the amounts of hemin, $\mathrm{TMB}$, and $\mathrm{H}_{2} \mathrm{O}_{2}$ and the incubation time were optimized. As shown in Figure S5A, the potential difference increases when increasing the concentration of TMB from 0.01 to $0.1 \mathrm{mM}$ and then tends to be constant at higher concentrations. Therefore, 
the concentration of $0.1 \mathrm{mM}$ was selected for further experiments. Figure S5B shows that the high potential difference can be obtained with $\mathrm{H}_{2} \mathrm{O}_{2}$ at concentrations higher than $0.2 \mathrm{mM}$. Thus, $0.2 \mathrm{mM} \mathrm{H}_{2} \mathrm{O}_{2}$ was chosen as the optimal value for antibiotic measurements. As illustrated in Figure S5C, the potential differences increase rapidly with the concentration of hemin until $0.1 \mu \mathrm{M}$, and thereafter the potential difference plateaus. Thus, the concentration of $0.1 \mu \mathrm{M}$ was chosen for the further experiments. The time for incubation of the analyte with the FMB was investigated in the range 15-75 min (Figure S5D). With increasing the incubation time, more signal reporter can be released and produce more Gquadruplex/hemin complexes, thus increasing the potential response. As the incubation time increases to $60 \mathrm{~min}$, the potential response tends to increase slowly. Therefore, $60 \mathrm{~min}$ was chosen for the subsequent experiments.

The proposed potentiometric aptasensing platform can perform "OR" logic functions by using the KANA (T1) and OTC (T2) as inputs. The absence and presence of each of them is defined as " 0 " and " 1 ", respectively. In the absence of both $\mathrm{T} 1$ and $\mathrm{T} 2$ inputs $(0,0)$, no signal reporter releases from the FMBs, and the potential change can be negligible (defined as output 0$)$. In the presence of either $\mathrm{T} 1(1,0)$ or $\mathrm{T} 2$ input $(0,1)$, or both of the $\mathrm{T} 1$ and $\mathrm{T} 2$ inputs $(1,1)$, the hybridization of the target with the aptamer sequence in the probe can cause a release of the signal reporter strand to assemble into the G-quadruplex. When combined with hemin, the G-quadruplex/hemin shows the peroxidase-like activity and catalyzes the $\mathrm{H}_{2} \mathrm{O}_{2}$-mediated oxidation of TMB to produce a chronopotentiometric response on the ISE (defined as output 1, Figure 2A). UV-vis spectroscopy (Figure 2B) and PAGE (Figure 2C) were applied to demonstrate the mechanism of the "OR" logic gate system. The obvious absorbance changes at 370 and $652 \mathrm{~nm}$ were observed with addition of $\mathrm{T} 1, \mathrm{~T} 2$, or a mixture of $\mathrm{T} 1$ and $\mathrm{T} 2$ to the system, which indicates the signal reporter released from the FMBs. The results of PAGE reveal that the aptamer-target binding events occur in the presence of $\mathrm{T} 1, \mathrm{~T} 2$, or a mixture of $\mathrm{T} 1$ and $\mathrm{T} 2$, which lead to the signal reporter released from the FMBs. Indeed, clear bands in the denatured gel were observed in lanes 4,5 , and 6 , which are consistent with the signal reporter band in land 2. The top bands in lanes 2, 4, 5, and 6 may be due to the sample stacking in the presence of the excess loading of samples. As shown in Figure 2D,E, only the absence of both inputs produces output 0 , while in the presence of either or both of the targets, an output 1 can be obtained. Since T1 has a higher binding constant and more flexibility to its aptamer than $\mathrm{T} 2{ }^{60,61}$ the potential change in the presence of $\mathrm{T} 2$ is less than that of $\mathrm{T} 1$. These results are in accordance with the data from the molecular docking as indicated above.

For an evaluation of the analytical performance of the proposed potentiometric aptasensing platform, different concentrations of KANA and OTC were analyzed. As shown in Figure 3A,C, the potential changes gradually increase with the increasing concentration of KANA and OTC, indicating that the aptamer-target binding event leads to the release of the signal reporter strand from the hybrid structure. Experiments reveal that the linear range for KANA or OTC was 10-100 $\mathrm{nM}$ (Figure 3B,D). The detection limits of KANA and OTC were calculated to be 7.5 and $9.8 \mathrm{nM}(3 \sigma)$, respectively. Compared to other reported methods (Tables S2 and S3 for KANA and OTC, respectively), the proposed assay not only exhibits high sensitivities but also could detect two antibiotics.

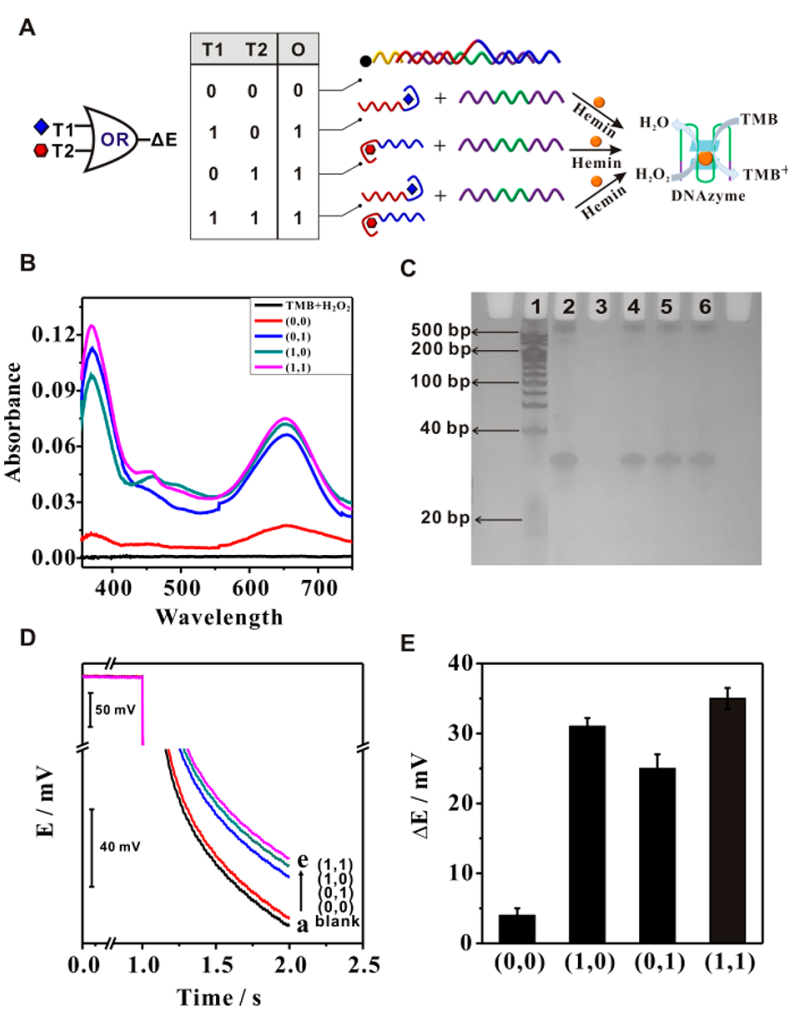

Figure 2. (A) Truth table and schematic illustration of the "OR" logic gate (T1, KANA; T2, OTC). (B) UV-vis absorbance of the "OR" logic gate upon treatments with $\mathrm{TMB}+\mathrm{H}_{2} \mathrm{O}_{2}$ as background, no $\mathrm{T} 1$ or T2 input $(0,0), \mathrm{T} 1$ input alone $(1,0), \mathrm{T} 2$ input alone $(0,1)$, and both $\mathrm{T} 1$ and $\mathrm{T} 2$ inputs $(1,1)$. (C) Polyacrylamide gel analysis of the OR logic gate. Different lanes represent the DNA markers (lane 1), signal reporter (lane 2), and DNA samples from different inputs: (0, $0)$ (lane 3); (1,0) (lane 4); (0, 1) (lane 5); and (1,1) (lane 6). (D) Potential response curves, and (E) potential changes of the "OR" logic gate upon treatments with no $\mathrm{T} 1$ or $\mathrm{T} 2$ input $(0,0), \mathrm{T} 1$ input alone $(1,0), \mathrm{T} 2$ input alone $(0,1)$, and both $\mathrm{T} 1$ and $\mathrm{T} 2$ inputs $(1,1)$. All experiments were done in a Tris- $\mathrm{HCl}$ buffer solution at $\mathrm{pH} 7.4$ (Tris, $10 \mathrm{mM}$; KCl, $20 \mathrm{mM} ; \mathrm{NaCl}, 200 \mathrm{mM}$ ). The hybrid-structuremodified magnetic beads of $25 \mu \mathrm{L}$ were incubated with the target for $1 \mathrm{~h}$ with gentle shaking. Other conditions are shown as follows: TMB, $0.1 \mathrm{mM} ; \mathrm{H}_{2} \mathrm{O}_{2}, 0.2 \mathrm{mM}$; T1 or T2, $100 \mathrm{nM}$; hemin, $100 \mathrm{nM}$; Gquadruplex, $100 \mathrm{nM}$. Error bars represent one standard deviation for three measurements.

In this study, a scramble DNA sequence was used as a control probe to validate the specificity of this method. As shown in Figure 4A, there is no significant potential change obtained for the control DNA. Moreover, the proposed potentiometric assay does not show any obvious potential changes when exposed to other antibiotics such as chloramphenicol (CAP), streptomycin (STR), ampicillin (AMP), gentamycin (GS), and spectinomycin (SPE) (Figure 4B). Therefore, the proposed logic gates can be employed for the detection of KANA and OTC with high selectivities.

For implementation of the "INHIBIT" logic gate, the target of $\mathrm{T} 1$ or $\mathrm{T} 2$ and the corresponding free aptamer $\mathrm{A} 1$ or $\mathrm{A} 2$ were used as the binary inputs (Figure 5A). The absence and presence of each of them are defined as " 0 " and " 1 ", respectively. When the input is $(0,0)$ or only with $\mathrm{A} 1$ or $\mathrm{A} 2$ $(1,0)$ alone, the output is " 0 ". However, when subjected to T1 or $\mathrm{T} 2$ alone $(0,1)$, the potential change increases distinctively, giving an output signal of " 1 ". When the two inputs (T1, A1; or T2, A2) appear simultaneously $(1,1)$, the free aptamer 

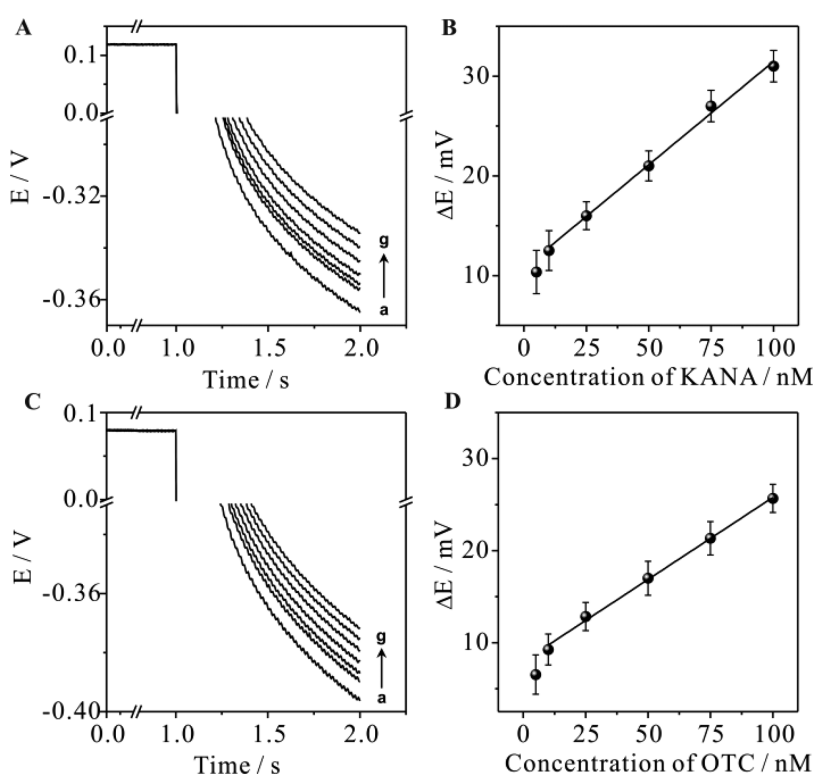

Figure 3. (A) Potential responses of the $\mathrm{H}_{2} \mathrm{O}_{2}$-mediated oxidation of TMB on the electrode in the buffer solution with (a) 0, (b) 5, (c) 10, (d) 25, (e) 50, (f) 75, and (g) $100 \mathrm{nM}$ of KANA. (B) Corresponding calibration plot for KANA detection. (C) Potential responses of the $\mathrm{H}_{2} \mathrm{O}_{2}$-mediated oxidation of TMB on the electrode in the buffer solution with (a) 0, (b) 5, (c) 10, (d) 25, (e) 50, (f) 75 and (g) 100 $\mathrm{nM}$ of OTC. (D) Corresponding calibration plot of the potential changes for OTC detection. Error bars represent one standard deviation of three measurements. Unless stated otherwise, the other conditions are as given for Figure 2.
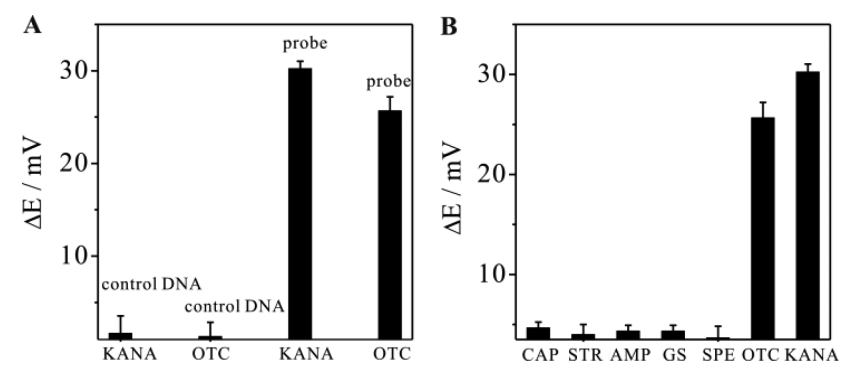

Figure 4. (A) Responses to KANA and OTC by using the probe and control DNA. (B) Responses to the targets and other interfering antibiotics including chloramphenicol (CAP), streptomycin (STR), ampicillin (AMP), gentamycin (GS), and spectinomycin (SPE). The concentrations of KANA and OTC were $100 \mathrm{nM}$, and those of other antibiotics were $1000 \mathrm{nM}$. Error bars represent one standard deviation of three measurements. Unless stated otherwise, the other conditions are as given for Figure 2.

could hybrid with the corresponding target to form a complex, which would efficiently inhibit the hybridization of the target with the aptamer sequence in the probe. Thus, the potential change decreases, and the output returns to "0" (Figure 5C,E).

As an input, the concentration of the free aptamer A1 or A2 was optimized. In the absence of $\mathrm{A} 1$ or $\mathrm{A} 2$, the formed DNAzyme has a strong catalytic activity toward the $\mathrm{H}_{2} \mathrm{O}_{2}$ mediated oxidation of TMB, thus producing an obvious potential change (Figure $5 \mathrm{~B}, \mathrm{D}$ ). With an increase in the amount of $\mathrm{A} 1$ or $\mathrm{A} 2$, there is a gradual decrease in readout signal (Figure S6). These results indicate that the hybridization between the free aptamer and its target disrupts the formation of G-quadruplex DNAzyme, resulting in a decrease of potential responses. In the presence of $10^{-6} \mathrm{M}$ of free aptamer,

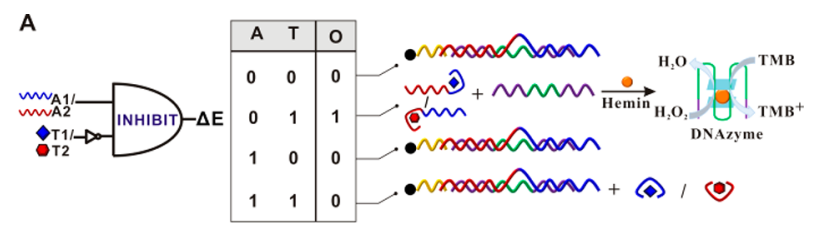

B
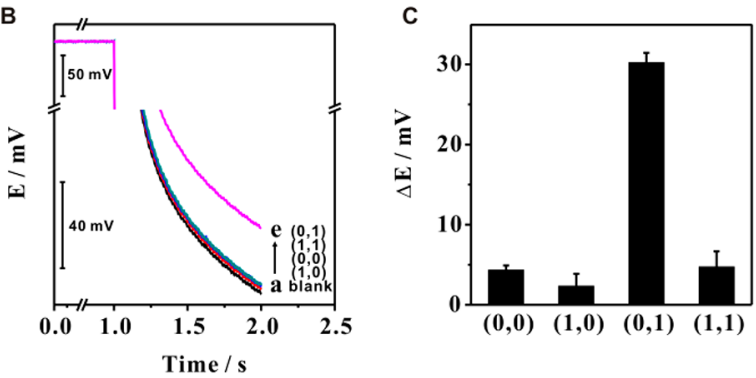

D

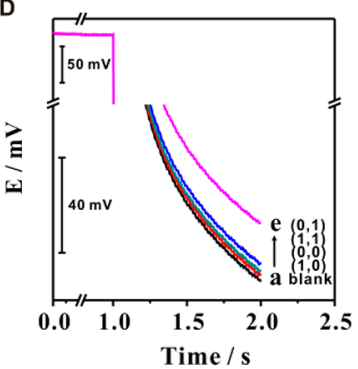

E

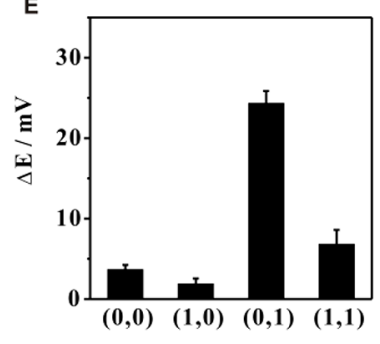

Figure 5. (A) Truth table and schematic illustration of the "INHIBIT" logic gate (T1, KANA; T2, OTC; A1, KANA aptamer; A2, OTC aptamer). (B, D) Potential response curves and (C, E) potential changes of the "INHIBIT" logic gate upon treatments with no $\mathrm{T} 1 / \mathrm{T} 2$ and $\mathrm{A} 1 / \mathrm{A} 2$ input $(0,0)$, only $\mathrm{A} 1 / \mathrm{A} 2$ input $(1,0)$, only $\mathrm{T} 1 /$ $\mathrm{T} 2$ input alone $(0,1)$, and both $\mathrm{T} 1 / \mathrm{T} 2$ and $\mathrm{A} 1 / \mathrm{A} 2$ inputs $(1,1)$. The hybrid-structure-modified magnetic beads of $25 \mu \mathrm{L}$ were incubated with the target for $1 \mathrm{~h}$ with gentle shaking. Other conditions are shown as follows: TMB, $0.1 \mathrm{mM} ; \mathrm{H}_{2} \mathrm{O}_{2}, 0.2 \mathrm{mM}$; T1 and T2, 100 $\mathrm{nM}$; $\mathrm{A} 1$ and A2, $1000 \mathrm{nM}$; hemin, $100 \mathrm{nM}$. Error bars represent one standard deviation for three measurements.

negligible changes in potential difference can be observed. Thus, $10^{-6} \mathrm{M}$ of the free aptamer was selected for the measurement of target. Experiments reveal that both KANA and OTC can be detected in the $\mathrm{nM}$ range.

The introduction of a sensing format based on the logic gate operations can be useful when there is no need for precise and quantitative measurements, but a rapid answer is important. ${ }^{27}$ For example, logic systems for the analysis of antibiotics in the aquaculture are important for immediate field-based decision making and therapeutic action. By combining the "OR" and "INHIBIT" gates, we were also able to make a high-throughput judgment about what targets were present in real samples according to the output results, and the logic operations and diagnosis are summarized in Table 1 . As shown in Table 1, there was no potential change (output 0 ) observed in test solution 1, which indicates that there was "no target", and we did not need to do other tests. However, when there was potential change observed (output 1) in test solution 1, the "INHIBIT" logic gate can be carried out by putting either A1 (test solution 2), A2 (test solution 3), or both of them (test solution 4) into the system to figure out which target was present in the sample.

Currently, potentiometric polymeric membrane ISEs have been widely used for the analysis of ions such as $\mathrm{Cl}^{-}, \mathrm{K}^{+}, \mathrm{Na}^{+}$, $\mathrm{Ca}^{2+}, \mathrm{Li}^{+}, \mathrm{NH}_{4}^{+}, \mathrm{NO}_{3}{ }^{-}, \mathrm{CO}_{3}{ }^{2-}, \mathrm{Cu}^{2+}$, and $\mathrm{Pb}^{2+}$ in soil, food, wastewater, and physiological electrolytes. ${ }^{63-67}$ They are in 
Table 1. Truth Table of Combinatorial Logic Gates for the Detection of KANA and OTC in the Sample

\begin{tabular}{|c|c|c|c|c|c|c|}
\hline \multicolumn{3}{|c|}{ inputs } & \multicolumn{4}{|c|}{ outputs } \\
\hline $\begin{array}{l}\text { test solution } \\
(\mathrm{T} 1, \mathrm{~T} 2)\end{array}$ & A1 & $\mathrm{A} 2$ & $\begin{array}{c}\text { no } \\
\text { target }\end{array}$ & $\begin{array}{c}\text { only } \\
\mathrm{T} 1\end{array}$ & $\begin{array}{l}\text { only } \\
\text { T2 }\end{array}$ & $\begin{array}{c}\mathrm{T} 1 \text { and } \\
\mathrm{T} 2\end{array}$ \\
\hline 1 & 0 & 0 & 0 & 1 & 1 & 1 \\
\hline 2 & 1 & 0 & $\backslash^{a}$ & 0 & 1 & 1 \\
\hline 3 & 0 & 1 & $\backslash$ & $\backslash$ & 0 & 1 \\
\hline 4 & 1 & 1 & $\backslash$ & $\backslash$ & 1 & 0 \\
\hline
\end{tabular}

${ }^{a}$ The " $\backslash$ " symbol means that the corresponding condition can be omitted. A1, aptamer for T1 (KANA); A2, aptamer for T2 (OTC); T1, KANA; T2, OTC.

principle adaptable for analyses of other clinically or environmentally relevant ions. While on-site detection can be achieved without any pretreatment except appropriate dilution, their applications to a number of different targets in real samples need to be explored. With the introduction of new (bio)receptors, highly sensitive and selective measurements of a broad range of different molecular targets other than ionic species can be expected. For validation of the practicability of the proposed potentiometric aptasensing platform, water samples were analyzed with the standard addition method. As shown in Table S4, the recoveries range from $92 \%$ to $98 \%$, while the standard deviations are in the range $2-5 \%$, indicating that the proposed potentiometric aptasensing platform offers good feasibility in practical analysis.

\section{CONCLUSIONS}

In conclusion, a novel potentiometric aptasensing platform for dual-analyte detection was designed by combiningG-quadruplex/hemin DNAzyme with logic gate operations. Both potentiometric "OR" and "INHIBIT" logic gates were fabricated, which enables the potentiometric aptasensing platform to achieve dual-target detection using a single potentiometric membrane electrode. Such a potentiometric aptasensing platform offers advantages as follows: (1) The DNAzyme can be incorporated into an aptamer binding event, which eliminates the probe labeling. Moreover, the signal amplification derived from catalysis of G-quadruplex/hemin DNAzyme allows a high sensitivity. (2) Potentiometry based on a polymeric membrane ion-selective electrode is one kind of simple, field-portable electrochemical methodology. Therefore, the potentiometric signal can serve as a promising output in logic gate systems. (3) Endowed with the G-quadruplex/hemin DNAzyme and logic gate operations, the potentiometric aptasensor is promising for the detection of multiplex analytes by simply changing the target aptamers in the probe sequences. Moreover, a multilevel logic operation can be performed by wiring different logic gates together. The versatile potentiometric aptasensing platform can be easily adapted for detection of a variety of analytes in bioanalysis and environmental monitoring.

\section{ASSOCIATED CONTENT}

\section{S Supporting Information}

The Supporting Information is available free of charge on the ACS Publications Web site. The Supporting Information is available free of charge on the ACS Publications website at DOI: 10.1021/acs.analchem.8b05971.

Additional experimental details, molecular docking and dynamics simulation, and figures including UV-vis spectra, potential responses, potential changes, absorbance changes, calibration plot, DNA structures, and effects of concentration and reaction time (PDF)

\section{AUTHOR INFORMATION}

\section{Corresponding Authors}

*Phone: +86 535 2109156. Fax: +86 535 2109000. E-mail: jwding@yic.ac.cn.

*E-mail: wqin@yic.ac.cn.

ORCID

Jiawang Ding: 0000-0002-8361-9102

Wei Qin: 0000-0002-9606-7730

\section{Author Contributions}

The manuscript was written through contributions of all authors. All authors have given approval to the final version of the manuscript.

Notes

The authors declare no competing financial interest.

\section{ACKNOWLEDGMENTS}

This work was financially supported by the National Natural Science Foundation of China (21575158, 21475148, and 41876108), The National Key Research and Development Program of China (2016YFC1400700), the Instrument Developing Project of the Chinese Academy of Sciences (Y728021021), and the Taishan Scholar Program of Shandong Province (TS20081159). We also acknowledge Enguang Lv and Dr. Shiling Zheng from Yantai Institute of Coastal Zone Research, who provided kind help for the molecular docking and PAGE measurement.

\section{REFERENCES}

(1) Bakker, E.; Pretsch, E. Angew. Chem., Int. Ed. 2007, 46, 56605668.

(2) Bobacka, J.; Ivaska, A.; Lewenstam, A. Chem. Rev. 2008, 108, 329-351.

(3) Lindner, E.; Gyurcsanyi, R. E. J. Solid State Electrochem. 2009, 13, $51-68$.

(4) Bakker, E. Anal. Chem. 2016, 88, 395-413.

(5) Papp, S.; Jágerszki, G.; Gyurcsányi, R. E. Angew. Chem., Int. Ed. 2018, 57, 4752-4755.

(6) Jágerszki, G.; Takacs, A.; Bitter, I.; Gyurcsányi, R. E. Angew. Chem., Int. Ed. 2011, 50, 1656-1659.

(7) Hu, J. B.; Stein, A.; Bühlmann, P. Angew. Chem., Int. Ed. 2016, $55,7544-7547$.

(8) Ding, J. W.; Li, B. W.; Chen, L. X.; Qin, W. Angew. Chem., Int. Ed. 2016, 55, 13033-13037.

(9) Liang, R. N.; Ding, J. W.; Gao, S. S.; Qin, W. Angew. Chem., Int. Ed. 2017, 56, 6833-6837.

(10) Ishige, Y.; Klink, S.; Schuhmann, W. Angew. Chem., Int. Ed. 2016, 55, 4831-4835.

(11) Bakker, E.; Bühlmann, P.; Pretsch, E. Chem. Rev. 1997, 97, 3083-3132.

(12) Bakker, E. TrAC, Trends Anal. Chem. 2014, 53, 98-105.

(13) Shvarev, A.; Bakker, E. J. Am. Chem. Soc. 2003, 125, 1119211193.

(14) Ding, J. W.; Qin, W. J. Am. Chem. Soc. 2009, 131, 1464014641.

(15) Hupa, E.; Vanamo, U.; Bobacka, J. Electroanalysis 2015, 27, 591-594.

(16) Vanamo, U.; Hupa, E.; Yrjana, V.; Bobacka, J. Anal. Chem. 2016, 88, 4369-4374.

(17) Crespo, G. A.; Afshar, M. G.; Bakker, E. Angew. Chem., Int. Ed. 2012, 51, 12575-12578. 
(18) Nagy, X.; Höfler, L. Anal. Chem. 2016, 88, 9850-9855.

(19) Cuartero, M.; Crespo, G. A.; Ghahraman Afshar, M.; Bakker, E. Anal. Chem. 2014, 86, 11387-11395.

(20) Crespo, G. A.; Cuartero, M.; Bakker, E. Anal. Chem. 2015, 87, $7729-7737$.

(21) Cuartero, M.; Crespo, G. A.; Bakker, E. Anal. Chem. 2016, 88, $5649-5654$.

(22) Cuartero, M.; Crespo, G. A.; Bakker, E. Anal. Chem. 2016, 88, $1654-1660$.

(23) Greenawalt, P. J.; Amemiya, S. Anal. Chem. 2016, 88, 58275834.

(24) Cuartero, M.; Ruiz, A.; Oliva, D. J.; Ortuno, J. A. Sens. Actuators, B 2017, 243, 144-151.

(25) Wang, X. W.; Balijepalli, A. S.; Meyerhoff, M. E. Electroanalysis 2015, 27, 1823-1828.

(26) Ding, J. W.; Yu, N. N.; Wang, X. D.; Qin, W. Anal. Chem. 2018, 90, 1734-1739.

(27) Katz, E.; Wang, J.; Privman, M.; Halámek, J. Anal. Chem. 2012, $84,5463-5469$.

(28) Katz, E. Int. J. Unconv. Comput. 2012, 8 (5-6), 339-346.

(29) Tam, T. K.; Strack, G.; Pita, M.; Katz, E. J. Am. Chem. Soc. 2009, 131, 11670-11671.

(30) Pischel, U. Angew. Chem., Int. Ed. 2007, 46, 4026-4040.

(31) Guliyev, R.; Ozturk, S.; Kostereli, Z.; Akkaya, E. U. Angew. Chem., Int. Ed. 2011, 50, 9826-9831.

(32) Casula, A.; Begines, P.; Bettoschi, A.; Fernandez-Bolanos, J. G.; Isaia, F.; Lippolis, V.; Lopez, O.; Picci, G.; Andrea Scorciapino, M.; Caltagirone, C. Chem. Commun. 2017, 53, 11869-11872.

(33) Lin, X. D.; Liu, Y. Q.; Deng, J. K.; Lyu, Y. L.; Qian, P. C.; Li, Y. F.; Wang, S. Chem. Sci. 2018, 9, 1774-1781.

(34) Fan, D. Q.; Fan, Y. C.; Wang, E. K.; Dong, S. J. Chem. Sci. 2018, 9, 6981-6987.

(35) He, K. Y.; Li, Y.; Xiang, B. B.; Zhao, P.; Hu, Y. F.; Huang, Y.; Li, W.; Nie, Z.; Yao, S. Z. Chem. Sci. 2015, 6, 3556-3564.

(36) Willner, I.; Zayats, M. Angew. Chem., Int. Ed. 2007, 46, 64086418.

(37) Iliuk, A. B.; Hu, L.; Tao, W. A. Anal. Chem. 2011, 83, 44404452.

(38) Tan, W. H.; Donovan, M. J.; Jiang, J. H. Chem. Rev. 2013, 113, $2842-2862$.

(39) Ding, J. W.; Gu, Y.; Li, F.; Zhang, H. X.; Qin, W. Anal. Chem. 2015, 87, 6465-6469.

(40) Zhu, L.; Li, C.; Zhu, Z.; Liu, D. W.; Zou, Y.; Wang, C. M.; Fu, H.; Yang, C. J. Anal. Chem. 2012, 84, 8383-8390.

(41) Wang, F.; Lu, C. H.; Willner, I. Chem. Rev. 2014, 114, 28812941.

(42) Zhang, H. Q.; Li, F.; Dever, B.; Li, X. F.; Le, X. C. Chem. Rev. 2013, 113, 2812-2841.

(43) Zhou, X. H.; Kong, D. M.; Shen, H. X. Anal. Chem. 2010, 82, 789-793.

(44) Li, W.; Li, Y.; Liu, Z. L.; Lin, B.; Yi, H. B.; Xu, F.; Nie, Z.; Yao, S. Z. Nucleic Acids Res. 2016, 44, 7373-7384.

(45) Brown, C. W.; Lakin, M. R.; Horwitz, E. K.; Fanning, M. L.; West, H. E.; Stefanovic, D.; Graves, S. W. Angew. Chem., Int. Ed. 2014, 53, 7183-7187.

(46) Kahan-Hanum, M.; Douek, Y.; Adar, R.; Shapiro, E. Sci. Rep. 2013, 3, 1535-1-1535-6.

(47) Zhang, L.; Zhang, Y. M.; Liang, R. P.; Qiu, J. D. J. Phys. Chem. C 2013, 117, 12352-12357.

(48) Zhang, Z.; Balogh, D.; Wang, F.; Willner, I. J. Am. Chem. Soc. 2013, 135, 1934-1940.

(49) Guo, Y. H.; Yao, W. R.; Xie, Y. F.; Zhou, X. D.; Hu, J. M.; Pei, R. J. Microchim. Acta 2016, 183, 21-34.

(50) Bi, S.; Yan, Y. M.; Hao, S. Y.; Zhang, S. S. Angew. Chem., Int. Ed. 2010, 49, 4438-4442.

(51) Chen, J. H.; Pan, J. F.; Chen, S. Chem. Sci. 2018, 9, 300-306.

(52) Guo, J. H.; Kong, D. M.; Shen, H. X. Biosens. Bioelectron. 2010, 26, 327-332.
(53) Elbaz, J.; Shlyahovsky, B.; Li, D.; Willner, I. ChemBioChem 2008, 9, 232-239.

(54) Xu, X. W.; Zhang, J.; Yang, F.; Yang, X. R. Chem. Commun. 2011, 47, 9435-9437.

(55) Liu, X.; Aizen, R.; Freeman, R.; Yehezkeli, O.; Willner, I. ACS Nano 2012, 6, 3553-3563.

(56) Zhou, M.; Du, Y.; Chen, C. G.; Li, B. L.; Wen, D.; Dong, S. J.; Wang, E. K. J. Am. Chem. Soc. 2010, 132, 2172-2174.

(57) Bobacka, J. Anal. Chem. 1999, 71, 4932-4937.

(58) Cheng, X. H.; Liu, X. J.; Bing, T.; Cao, Z. H.; Shangguan, D. H. Biochemistry 2009, 48, 7817-7823.

(59) Gao, F.; Zhou, H. F.; Li, W.; Zhang, X. R. PLoS One 2012, 7, No. e39251.

(60) Song, K. M.; Cho, M.; Jo, H.; Min, K.; Jeon, S. H.; Kim, T.; Han, M. S.; Ku, J. K.; Ban, C. Anal. Biochem. 2011, 415, 175-181.

(61) Kwon, Y. S.; Raston, N. H. A.; Gu, M. B. Chem. Commun. 2014, $50,40-42$.

(62) Wang, X. W.; Yang, Y. G.; Li, L.; Sun, M. S.; Yin, H. G.; Qin, W. Anal. Chem. 2014, 86, 4416-4422.

(63) Hecht, M. H.; Kounaves, S. P.; Quinn, R. C.; West, S. J.; Young, S. M. M.; Ming, D. W.; Catling, D. C.; Clark, B. C.; Boynton, W. V.; Hoffman, J.; DeFlores, L. P.; Gospodinova, K.; Kapit, J.; Smith, P. H. Science 2009, 325, 64-67.

(64) Athavale, R.; Dinkel, C.; Wehrli, B.; Bakker, E.; Crespo, G. A.; Brand, A. Environ. Sci. Technol. Lett. 2017, 4, 286-291.

(65) Athavale, R.; Kokorite, I.; Dinkel, C.; Bakker, E.; Wehrli, B.; Crespo, G. A.; Brand, A. Anal. Chem. 2015, 87, 11990-11997.

(66) Cuartero, M.; Crespo, G. A.; Bakker, E. Anal. Chem. 2015, 87, 8084-8089.

(67) Mousavi, M. P. S.; Ainla, A.; Tan, E. K. W.; Abd El-Rahman, M. K.; Yoshida, Y.; Yuan, L.; Sigurslid, H. H.; Arkan, N.; Yip, M. C.; Abrahamsson, C. K.; Homer-Vanniasinkam, S.; Whitesides, G. M. Lab Chip 2018, 18, 2279-2290. 